\title{
A brief introduction to China's new Drug Administration Law and its impact on medications for rare diseases
}

\author{
Yueqiang Wang ${ }^{1}$, Duo Chen ${ }^{1}$, Jiangjiang $\mathrm{He}^{1,2, *}$ \\ ${ }^{1}$ Shanghai Health Development Research Center (Shanghai Medical Information Center), Shanghai, China; \\ ${ }^{2}$ School of Public Health, Fudan University, Shanghai, China.
}

\begin{abstract}
Summary The Drug Administration Law of the People's Republic of China (amended in August 2019) is a major piece of legislation governing drug administration in China. This law seeks to improve health legislation; to achieve this, it defines the concepts of fake drugs and inferior drugs and their differences, it emphasizes the regulation of reliability, it standardizes online drug sales, it encourages technological innovation, and it specifies legal liability and punishment through legislative amendments. The Drug Administration Law is characteristic of responsive legislation, and it guarantees a right to health for citizens. The law provides for priority review and approval of new drugs for diseases like rare diseases, it encourages the domestic manufacturing and development of new drugs for rare diseases, and it provides a firm legal basis for medications to treat rare diseases under the Healthy China strategy.
\end{abstract}

Keywords: Drug Administration Law, characteristics of legislation, implementation of the law, rare disease, orphan drug

\section{Introduction}

The Drug Administration Law of the People's Republic of China is the basic law governing drug manufacturing, usage, and administration. The newly amended Drug Administration Law of the People's Republic of China (herein after referred to as the "new Drug Administration Law") was passed in August 2019, and it took effect on December 1, 2019. The amendment signals that China has upgraded its "drug legislation" with numerous innovations. More importantly, the new Drug Administration Law has now provided a legal framework for a priority review system for pediatric drugs, drugs in short supply, drugs for serious infectious diseases, and drugs for rare diseases. The Law actively promotes and provides for resources to research and develop those drugs, and especially those for rare diseases, thus providing legal support to ensure the supply of medications for rare diseases.

\footnotetext{
*Address correspondence to:

Jiangjiang He, Shanghai Health Development Research Center (Shanghai Medical Information Center), No.1477 Beijing (W) Road, Jing'an District, Shanghai 200040, China. E-mail: hejiangjiang@shdrc.org
}

\section{Main aspects of the legislation}

\subsection{Legal protection of the "right to health" for Chinese citizens}

The right to health is a basic right specified in the Chinese Constitution (1). The Law clearly stipulates that the new Drug Administration Law is intended "to ensure drug safety and protect the public's legitimate rights and interests and to protect and promote public health" in Chapter 1, Article 1; similarly, Article 3 states that "drug administration shall focus on public health". Chapter 2, Article 16 states that the State will implement priority review and approval for drugs in short supply that are urgently needed clinically, for new drugs to prevent and treat serious infectious diseases, for drugs to treat rare diseases, and for pediatric drugs. Ethics review, informed consent, clinical risks, and other aspects of "conducting clinical trials on drugs" are stipulated in detail. The new Drug Administration Law is based on a right to health, protecting the legitimate rights of Chinese citizens. This concept is intended to facilitate the adoption of national strategies like "Healthy China" and also to accord with international norms of human rights protection in China. 


\subsection{Reinforcing regulation during and after drug administration}

The Chinese Government has promoted in-depth reforms "to streamline administration, delegate powers, and improve regulation and services" to spur innovation in regulatory concepts, systems, and methods, and to establish and improve a new regulatory system connecting the entire regulatory process before and after drugs are marketed (2). The new Drug Administration Law stipulates that "departments of drug administration will create records of the reliability of drug safety, increase the frequency of supervision and inspections for entities with a record of unreliability, and potentially implement joint punishment pursuant to State regulations". The Law specifies a system for sharing information and a drug traceability system. Regulation of reliability and regulation of information are used to achieve drug traceability, to promote regulation of drug safety, and to improve regulatory efficiency.

\subsection{Implementation of internet-related provisions to safeguard the drug supply}

Internet-related provisions are crucial to reforming the drug supply. The supply of quality medical resources has been effectively promoted through close coordination with the healthcare industry and innovation (3). Chapter 6, Articles 61 and 62 of the new Drug Administration Law describe "online drug sales" in detail. The Law encourages the online sales of drugs, but it prohibits the online sales of drugs specially administered by the State. Online drug distributors are required to have the same qualifications as offline entities. Entities operating third-party platforms where drugs are available must file for approval, have their qualifications reviewed, and follow other legal procedures so that regulations of drug sales online and offline are standardized. Other laws and regulations like the Measures for the Supervision and Administration of Drug Sales Online have been issued to further standardize and facilitate the healthy development of drug sales online.

\subsection{Reinforcing drug administration and intensifying punishments for unlawful acts}

The new Drug Administration Law specifies liabilities for pharmaceutical companies and legal sanctions to crack down on corruption in the pharmaceutical industry, and it stresses the primary responsibility of pharmaceutical companies, and especially persons responsible. Drawing upon legislative concepts in the Law for the Protection of Consumer Rights and Interests, the new Drug Administration Law includes liability for compensation. A system of civil liability for drug harms has been established, and the administrative liability of drug regulators is specified.

\section{Major results of the legislation}

\subsection{Developing and improving extensive laws and regulations on drug administration}

The objectives, chapters, structure, rationale, and principles of the new Drug Administration Law have been substantially revised from the former version. The former Drug Administration Law had 10 chapters with 104 articles (2015 Revision) while the new Drug Administration Law has 12 chapters with 155 articles. Entities authorized to market drugs, drug stockpiles and supply, drug post-marketing management, and other chapters have been added to the new Law (see Table 1).

\subsection{Promoting the optimization of scientific and rigorous health legislation}

The Basic Medical Care and Health Promotion Law is intended to legally specify for the first time that health is a basic right of citizens. The Healthy China strategy has been implemented (4), and it clearly specifies important issues like the National Essential Drugs System and the "drug supply". The new Drug Administration Law takes the national legislative framework of the Vaccine Administration Law into account and it excludes regulations related to vaccines, a special type of drug (5), in order to allow the strictest regulation and administration of vaccines. The new Drug Administration Law focuses on the link between drug legislation and the scope of specially targeted laws, helping to improve health legislation in China.

\subsection{Embodying the rule of law and flexibly controlling and regulating drug administration}

The pharmaceutical industry is at the leading edge of scientific research and innovation. Problems spanning law and science and technology are continually appearing with the rapid development of information technology and artificial intelligence (6). The new Drug Administration Law has reiterated the legal concept of drugs and for the first time has adopted a "general" legislative approach to the definition of drugs instead of a "specific" approach. The legal concept of a "drug" was defined in the Supplementary Provisions of the old version of the Law, but it is now defined in Article 2 under Chapter 1, General Principles. Article 5 in the same chapter encourages the development of and innovation in drugs. The amendment of the law is an extensive revision. Accordingly, the entire text of the amended law needs to be read (7).

Amendment of the legislation was approached scientifically, i.e. "from tweaks to extensive revision", and various aspects of the Drug Administration Law, 
Table 1. Table comparing the revised chapters in the new and former versions of the Drug Administration Law

\begin{tabular}{|c|c|c|c|c|}
\hline Name of the law & new Drug Administration Law & & former Drug Administration Law & \\
\hline \multirow{13}{*}{$\begin{array}{l}\text { Chapters and } \\
\text { number of articles }\end{array}$} & Chapter 1 General Principles & 15 & Chapter 1 General Principles & 6 \\
\hline & $\begin{array}{c}\text { Chapter } 2 \text { Drug Research, Development, and } \\
\text { Registration }\end{array}$ & 14 & - & - \\
\hline & Chapter 3 Entities Authorized to Market Drugs & 11 & - & - \\
\hline & Chapter 4 Drug Manufacturing & 10 & Chapter 2 Control over Drug Manufacturers & 7 \\
\hline & Chapter 5 Drug Distribution & 18 & Chapter 3 Control over Drug Distributors & 8 \\
\hline & $\begin{array}{c}\text { Chapter } 6 \text { Pharmacy Administration in Medical } \\
\text { Institutions }\end{array}$ & 8 & $\begin{array}{c}\text { Chapter } 4 \text { Control over Pharmaceuticals in Medical } \\
\text { Institution }\end{array}$ & 7 \\
\hline & Chapter 7 Post-marketing Management & 7 & Chapter 5 Post-marketing Management & 23 \\
\hline & - & & Chapter 6 Control over Drug Packaging & 3 \\
\hline & Chapter 8 Drug Pricing and Advertising & 8 & Chapter 7 Control over Drug Pricing and Advertising & 8 \\
\hline & Chapter 9 Drug Stockpile and Supply & 6 & - & - \\
\hline & Chapter 10 Supervision and Administration & 6 & Chapter 8 Supervision and Administration & 9 \\
\hline & Chapter 11 Legal Liability & 48 & Chapter 9 Legal Liability & 28 \\
\hline & Chapter 12 Supplementary Provisions & 4 & Chapter 10 Supplementary Provisions & 5 \\
\hline Total & 12 chapters, 115 articles & & 10 chapters, 104 articles & \\
\hline
\end{tabular}

from concepts to content, have been altered. This helped to improve the logical consistency of the regulatory system in the Law, the completeness of revisions, and the feasibility of content stipulated in the Law. As a result, pharmaceutical affairs legislation in China has been revised and improved and better legal safeguards have been put in place for domestic drug regulation (8).

\subsection{Actively responding to Chinese society's concerns about medications}

Transitioning to a responsive legislative approach is inevitable as the rule of law develops in China (9). The core of a responsive legislative approach is: to respond to society, to reduce repression but to increase awareness, efforts, and openness in accordance with legislative objectives, to combine openness and legitimacy, to provide a legal foundation, to provide substantive justice, to serve the public interest, and to uphold society's ideals (10). The new Drug Administration Law focuses on societal needs like being able "to purchase anticancer drugs on the overseas market on behalf of a party wishing to do so". For the first time, the Law defines the scope of fake drugs and inferior drugs and it differentiates their legal attributes to help identify fake drugs and inferior drugs more precisely and to punish their sellers. Drugs that are marketed overseas but that have not been approved domestically are no longer treated as fake drugs. Punishment imposed on offenders who import small quantities of drugs marketed overseas that have not been approved domestically may be reduced in some cases; if no harm is caused or treatment is not delayed, offenders can be exempted from punishment. Legally addressing societal issues in pharmaceuticals, meeting vast legislative needs, and reinforcing the public's respect for the law will help to shape the practical aspects of legislation and increase its effectiveness.

\section{Impact on medications for rare diseases}

\subsection{Current medications for rare diseases in China}

Rare diseases are not clearly defined in China, and patients depend almost entirely on imports. This represents a major obstacle to protection of the right to health of patients with rare diseases. One major problem is the limited manufacture of drugs to treat rare diseases. Companies lack the initiative to develop, license, and manufacture drugs for rare diseases because of the small population of patients with rare diseases and unclear benefit, the long cycle of clinical trials and unpredictable results, unclear import or regulatory policies concerning drugs in certain categories, and the uncertainty of medical insurance reimbursement. A second major problem is the lack of medications for rare diseases. There is no medication to treat $95 \%$ of the rare diseases in China. Of the 121 diseases included in the First Rare Diseases List, 44 can be treated with 88 medications but only 35 of those medications are available in China. Many innovative drugs to treat rare diseases are not imported, and medications are unavailable to many patients (11). A third major problem is the cost of drugs for rare diseases. Of 55 medications for rare diseases that are available in China, only 29 are included in the National Health Insurance Reimbursed Drug List, and only 9 are reimbursed at A level. High drug prices directly limit reimbursement for drugs to treat rare diseases and hamper obtaining approval for marketing, further influencing the manufacturing and development of those drugs. The societal dilemma is the limited applicability of "orphan drugs" to treat rare diseases compared to more widely applicable drugs. 


\subsection{Basis for policies related to medications for rare diseases in China}

Social trends are encouraging the development of innovative drugs and accelerating review and approval, so the Chinese Government has initiated innovations in its policies on drugs to treat rare diseases. In 2015, the National Medical Products Administration (NMPA) issued the "Notice on Polices for Drug Registration, Review, and Approval". The Notice clearly stated that applications could be submitted for innovative orphan drugs individually and that their review and approval would be accelerated. In October 2017, the General Office of the CPC Central Committee and General Office of the State Council of the People's Republic of China issued their "Opinions on further reform of the review and approval system and encouraging innovations in drugs and medical devices". The document stipulated that drugs and medical devices to treat rare diseases that had been approved abroad could be conditionally approved for use in China, and it clearly supported the development of drugs and medical devices to treat rare diseases. In December 2017, the NMPA issued "Opinions on encouraging drug innovation and implementing priority review and approval"; rare diseases were included in the scope of priority review and approval. The document also stated that "applications to reduce the number of clinical trial subjects or for exemption from clinical trials could be submitted for rare diseases and other specific diseases". The Center for Drug Evaluation will decided whether to approve an application or not based on technical review and the actual status of Chinese patients. In May 2019, the National Health Commission, Ministry of Science and Technology, Ministry of Industry and Information Technology, NMPA, and National Administration of Traditional Chinese Medicine jointly published the First Rare Diseases List, which included 121 diseases. This is an important step in supporting medications for rare diseases. Areas and regions like Shanghai, Guangdong Province, and Shandong Province have also actively explored measures to encourage the development of drugs to treat rare diseases and the prevention and treatment of rare diseases via local legislation. A point worth mentioning is that these efforts involve inherent problems like fragmented policies, defective regulations, and limited legal reach. The problems of development and approval of "orphan drugs" cannot be solved by local regulation alone.

\subsection{Reinforcing the law basis for approval of drugs to treat rare diseases}

Chapter 9, Article 96 of the new Drug Administration Law stipulates that the State will encourage the research, development, and manufacture of drugs in short supply and implement priority review and approval for drugs in short supply that are urgently needed clinically, for new drugs to prevent and treat serious infectious diseases, and for drugs to treat rare diseases. The Law provides special legal protections for medications that are useful in treating rare diseases. From a legal perspective, reforms have resulted in a drug review and approval system that aims to encourage the pharmaceutical industry to independently conduct research, development, and innovation. The reforms "to streamline administration, delegate powers, and improve regulation and services" in drug regulation are based in law and filled the gap caused by the fact that drugs to treat rare diseases in China are almost entirely imports and the lack of specialized legislation governing research and development. From society's perspective, the Law has helped to unshackle medications for rare diseases and to enhance the ability of Chinese pharmaceutical companies to share information internationally and engage in technical cooperation. This has increased the accessibility to medications for rare diseases and thus better protects the right to health of patients with rare diseases both at home and abroad.

\section{References}

1. Chen YL. Study on the Legislation of Health Rights and Duties for Citizen: Comment on Chapter II of the Draft of Basic Medicine and Health Promotion Act. Political Science and Law. 2018; 5:100. (in Chinese)

2. Yang JG. How to connect the new Drug Administration Law with the Vaccine Administration Law? http:// news.eastday.com/eastday/13news/auto/news/ society/20190826/u7ai8778344.html (accessed August 26, 2019) (in Chinese)

3. Meng Q. Internet+ assists in the supply-side reform in health and medical care industry. Chinese Journal of Health Informatics and Management. 2016; 2:105. (in Chinese)

4. Tian K, Yu TX, Mao XY. The analysis of essential medicine system in China from the perspective of citizens' health rights - also review on "drug supply" in Basic Medical Care and Health Promotion Law (Draft). China Health Law. 2018; 26:1-6. (in Chinese)

5. Qu T, Zhao WJ. China will establish and improves upon a drug traceability system. http://www.xinhuanet. com//politics/2019-08/26/c_1124923782.htm (accessed August 26, 2019) (in Chinese)

6. Zheng YS. Solving the technology-neutral problem rethinking on the relation between law and technology from the perspective of nomology.Journal of the East China University of Politics \& Law. 2018; 21:85-97. (in Chinese)

7. Zhang CD. Research on enacting, revising, repelling laws from the perspective of comprehensively deepening the reform. Journal of the Central Institute of Socialism. 2018; 2:24-29. (in Chinese)

8. China Pharmaceutical News. Transforming the results of drug reform into law: the second revision of Drug Administration Law is upcoming. http://epaper.cnpharm. com/zgyyb/html/2019-04/24/content_589574.htm?div=-1 (accessed August 29, 2019) (in Chinese) 
9. Zhang HL. On the responsive legislation mode. Shandong University.2012; 11. https://www.docin.com/ p-1629967905.html (accessed August 27 2019) (in Chinese)

10. Wei Y. Discussion on responsive la--Interpretation on Law and Society in Transition: Toward Responsive Law. http://www.xueshutianxia.com/dissertation/ detail/1001310000696269.html (accessed August 29, 2019) (in Chinese)

11. Zhang SY. The Care for Rare Diseases, Starting from Medication. China Health. 2019; 5:64-65. (in Chinese)

(Received September 22, 2019; Revised November 2, 2019; Accepted November 12, 2019) 